\title{
Systematic review of acute levodopa and apomorphine challenge tests in the diagnosis of idiopathic Parkinson's disease
}

\author{
C E Clarke, P Davies
}

\begin{abstract}
Objectives-To perform a systematic review of studies examining the diagnostic accuracy of acute challenge tests with levodopa and/or apomorphine in parkinsonian syndromes to assess their value in the diagnosis of idiopathic Parkinson's disease.
\end{abstract}

Methods-A literature search including Medline and the Cochrane Library was performed for studies published in any language comparing acute levodopa and/or apomorphine response with chronic levodopa therapy in parkinsonian syndromes. Abstracted sensitivity and specificity data were summarised using variance weighting and conditional logistic regression for studies comparing two challenge tests.

Results-Thirteen studies were located: four examining de novo patients and nine examining patients with well established idiopathic Parkinson's disease and nonparkinsonian conditions. Despite the significant heterogeneity in the methodologies employed, the comparable results suggest that this had little effect on the accuracy of the tests. The sensitivity for the diagnosis of established idiopathic Parkinson's disease was: apomorphine 0.86 (95\% confidence interval (95\% CI) 0.78-0.94), acute levodopa 0.75 (95\% CI 0.64-0.85), and chronic levodopa therapy 0.91 (95\% CI $0.85-0.99)$. The specificity for the diagnosis of established idiopathic Parkinson's disease was: apomorphine 0.85 (95\% CI 0.74-0.96), acute levodopa 0.87 (95\% CI 0.77-0.97), and chronic levodopa therapy 0.77 (95\% CI 0.61-0.93). The number of patients positive for each test divided by the number with clinically diagnosed de novo disease was: apomorphine $0.63(95 \%$ CI $0.56-0.70)$, acute levodopa $0.69(95 \%$ CI $0.59-0.80)$, and chronic levodopa therapy 0.76 (95\% CI 0.70-0.82).

Conclusions-The accuracy of the acute levodopa and apomorphine challenge tests is similar to, but not superior than, that of chronic levodopa therapy in the diagnosis of idiopathic Parkinson's disease. As most patients will be given chronic dopamimetic therapy, these tests add nothing while causing significant adverse events and additional cost. (f Neurol Neurosurg Psychiatry 2000;69:590-594)

Keywords: Parkinson's disease; apomorphine; levodopa; systematic review
Recent pathological studies have shown that the clinical diagnosis of idiopathic Parkinson's disease is incorrect in around $25 \%$ of cases. ${ }^{1}$ Attempts in the past to improve this diagnostic inaccuracy with various investigative methods have been largely unrewarding. Anal and urethral sphincter electromyography can identify some later cases of multiple system atrophy but it is poorly tolerated by some patients. ${ }^{2}$ It has been suggested that the clonidine growth hormone $(\mathrm{GH})$ stimulation test can identify cases of multiple system atrophy by their poor $\mathrm{GH}$ response, ${ }^{3}$ however other groups have also shown a poor response in idiopathic Parkinson's disease. ${ }^{4}$ SPECT and PET can demonstrate dopamine deficiency states and postsynaptic striatal damage, but they still cannot reliably differentiate Parkinson's disease from other akinetic-rigid syndromes. ${ }^{6}$ Magnetic resonance imaging volumetry may prove more reliable than standard cross sectional MRI and may be more readily available in the United Kingdom. ${ }^{7}$

There remains the need for a simple, inexpensive and reliable diagnostic test which is acceptable to patients and readily available. In the search for such an investigation, the response of parkinsonian patients to acute challenge tests with levodopa or apomorphine continue to be used by many clinicians to confirm or refute the diagnosis of idiopathic Parkinson's disease. The object of the present study was to perform a systematic review and meta-analysis of studies examining the diagnostic accuracy of acute challenge tests with levodopa or apomorphine in parkinsonian syndromes to assess whether they are of value in the diagnosis of idiopathic Parkinson's disease.

\section{Materials and methods}

A literature search was performed using Medline for the years 1966-September 1999 and the Cochrane Library (1999 Issue 3). The search terms used were Parkinson's disease and its derivations, multiple system atrophy, and progressive supranuclear palsy cross referenced with apomorphine and levodopa, all as $\mathrm{MeSH}$ headings and textwords. The reference lists of the identified studies were examined for further studies. Studies were included if they reported the results of acute levodopa or apomorphine challenges in patients with akinetic-rigid syndromes. All languages were included and investigators were contacted for additional information where necessary.

Diagnostic criteria were abstracted from each report in addition to standard descriptive statistics. Sensitivity and specificity analysis 
Table 1 Characteristics of studies where patients with an established clinical diagnosis of idiopathic Parkinson's disease (IPD) or another parkinsonian condition were examined for response to apomorphine, acute levodopa, or chronic levodopa

\begin{tabular}{|c|c|c|c|c|c|c|c|c|c|c|}
\hline \multirow{2}{*}{$\begin{array}{l}\text { First author/ } \\
\text { ref No }\end{array}$} & \multirow{2}{*}{$\begin{array}{l}\text { Year of } \\
\text { publication }\end{array}$} & \multicolumn{3}{|c|}{ Patients (n) } & \multirow{2}{*}{$\begin{array}{l}\text { Assessment } \\
\text { methods }\end{array}$} & \multirow{2}{*}{$\begin{array}{l}\text { Threshold for } \\
\text { response }\end{array}$} & \multirow{2}{*}{$\begin{array}{l}\text { Number of tests for } \\
\text { positive result }\end{array}$} & \multirow{2}{*}{$\begin{array}{l}\text { Follow up for } \\
\text { chronic LD }\end{array}$} & \multirow[b]{2}{*}{ Drug } & \multirow[b]{2}{*}{ Dose (mg) } \\
\hline & & $I P D$ & Non-IPD & Total & & & & & & \\
\hline Oertel $^{13}$ & 1989 & 23 & 19 & 42 & $\begin{array}{l}\text { Hoehn and } \\
\text { Yahr }\end{array}$ & Unclear & Unclear & NA & $\mathrm{APO}$ & $1 / 2 / 4 / 5 / 10$ \\
\hline Hughes $^{14}$ & 1990 & 65 & 35 & 100 & $\begin{array}{l}\text { Webster } \\
\text { Tapping } \\
12 \mathrm{~m} \text { walk } \\
\text { Tremor } \\
\text { Webster }\end{array}$ & $\begin{array}{l}\text { Unclear } \\
>15 \% \\
>25 \% \\
>2 \text { points } \\
>3 \text { points }\end{array}$ & One of four & Variable & $\begin{array}{l}\text { Acute LD } \\
\text { APO } \\
\text { Chronic LD }\end{array}$ & $\begin{array}{l}275 \\
1.5 / 3.0 / 4.5 \\
<1000\end{array}$ \\
\hline $\mathrm{D}^{\prime} \operatorname{Costa}^{15}$ & 1991 & 20 & 8 & 28 & $\begin{array}{l}\text { Tapping } \\
6 \text { m walk }\end{array}$ & $\begin{array}{l}>15 \% \\
>15 \%\end{array}$ & One of two & 1 month & $\begin{array}{l}\text { APO } \\
\text { Chronic LD }\end{array}$ & $\begin{array}{l}1 / 2 / 4 / 5 / 8 / 10 \\
\text { Variable }\end{array}$ \\
\hline Schelosky ${ }^{16}$ & 1993 & 28 & 13 & 41 & $\begin{array}{l}\text { UPDRS III } \\
\text { Tapping } \\
10 \mathrm{~m} \text { walk }\end{array}$ & $\begin{array}{l}>30 \% \\
>30 \% \\
>15 \%\end{array}$ & One of three & NA & $\mathrm{APO}$ & $2.0 / 3.5 / 5.0$ \\
\hline Bonuccelli ${ }^{17}$ & 1993 & 30 & 7 & 37 & $\begin{array}{l}\text { Tremor } \\
\text { Tapping } \\
\text { Rigidity }\end{array}$ & $\begin{array}{l}>25 \% \\
>15 \% \\
>25 \%\end{array}$ & $\begin{array}{l}\text { Tremor \& one } \\
\text { other }\end{array}$ & NA & $\mathrm{APO}$ & $0.7 / 3.5 / 7.0$ \\
\hline Linazasoro $^{18}$ & 1993 & 25 & 18 & 43 & $\begin{array}{l}\text { Tapping } \\
20 \text { m walk } \\
\text { Tremor }\end{array}$ & $\begin{array}{l}>15 \% \\
>25 \% \\
>2 \text { points }\end{array}$ & One of three & NA & $\mathrm{APO}$ & $1.5 / 3 / 6 / 7.5$ \\
\hline Roth $^{19}$ & 1994 & 23 & 16 & 39 & Columbia & $>30 \%$ & Only one & NA & $\mathrm{APO}$ & $0.05 \mathrm{mg} / \mathrm{kg}$ \\
\hline Miranda $^{20}$ & 1995 & 22 & 10 & 32 & $\begin{array}{l}\text { Tapping } \\
12 \mathrm{~m} \text { walk } \\
\text { Webster }\end{array}$ & $\begin{array}{l}>15 \% \\
>25 \% \\
>3 \text { points }\end{array}$ & One of three & NA & $\mathrm{APO}$ & $1.5 / 3.0 / 5.0$ \\
\hline Zappia $^{21}$ & 1997 & 70 & 4 & 74 & UPDRS III & $>20 \%$ & Only one & 6 months & $\begin{array}{l}\text { Acute LD } \\
\text { Chronic LD }\end{array}$ & $\begin{array}{l}275 \\
<1000\end{array}$ \\
\hline
\end{tabular}

and also logistic regression analysis were used to compare studies for particular challenge tests. Conditional logistic regression analysis was used to compare those studies in which patients received both challenge tests and their outcomes were consequently matched by patient. As sample frequencies were sometimes small, confidence intervals for sensitivities and specificities were obtained using the exact probability routines of the statistical package EGRET (Cytel Software Corporation). Metaanalysis for each challenge test was obtained by the variance weighting method for pooling proportions (Fleiss) and testing for homogeneity between studies. ${ }^{8}$ In the meta-analysis, continuity corrections of adding 0.5 to frequencies were used as some frequencies were zero. Logistic regression analysis to test for significant variation in the odds ratios between studies was also used.

\section{Results}

Thirteen studies met the inclusion criteria for the review. Four examined de novo patients only in whom the diagnosis of idiopathic Parkinson's disease was relatively recently made. ${ }^{9-12}$ Nine studies investigated a group of patients who were clinically thought to have had the disease for some time, along with a separate group who were thought to have nonparkinsonian conditions such as multiple system atrophy and progressive supranuclear palsy. ${ }^{13-21}$

Most challenges were performed as a day case admission after domperidone pretreatment. The details of apomorphine titration varied from study to study with various maximum doses (table 1). A standard dose of levodopa plus decarboxylase inhibitor of 275 mg was used in the two studies examining this agent. The maximum dose of pure levodopa in the chronic challenges was in general $1000 \mathrm{mg}$, but the duration of treatment varied from 1 to 6 months (table 1). The assessment methods used had a common theme throughout the studies as many were based on the methodology of Hughes et al. ${ }^{14}$ They included standard motor impairment clinical rating scales, such as the unified Parkinson's disease rating scale (UPDRS) motor component, the Webster scale, and the Hoehn and Yahr scale, along with timed tests such as repeated tapping and walking a set distance. The last varied considerably between trials. The thresholds for a positive response to these tests also varied widely. Only one group based the thresholds for response on receiver-operator curves to get the best balance between sensitivity and specificity. ${ }^{11}$ However,

Table 2 Characteristics of studies where patients with newly diagnosed idiopatic Parkinson's disease (IPD) were examined for the response to apomorphine, acute levodopa, or chronic levodopa

\begin{tabular}{|c|c|c|c|c|c|c|c|c|}
\hline First author & $\begin{array}{l}\text { Year of } \\
\text { publication }\end{array}$ & $\begin{array}{l}\text { Patients } \\
\text { (n) }\end{array}$ & Assessments & Threshold & $\begin{array}{l}\text { Number of tests } \\
\text { for positive } \\
\text { result }\end{array}$ & $\begin{array}{l}\text { Follow up for } \\
\text { chronic LD }\end{array}$ & Drug & Doses (mg) \\
\hline Hughes $^{10}$ & 1991 & 45 & $\begin{array}{l}\text { Tapping } \\
20 \mathrm{~m} \text { walk } \\
\text { Tremor } \\
\text { Webster }\end{array}$ & $\begin{array}{l}>15 \% \\
>25 \% \\
>2 \text { points } \\
>3 \text { points }\end{array}$ & One of four & Variable & $\begin{array}{l}\text { Acute LD } \\
\text { APO } \\
\text { Chronic LD }\end{array}$ & $\begin{array}{l}275 \\
1.5 / 3.0 / 4.5 \\
<1000\end{array}$ \\
\hline Gasser $^{11}$ & 1992 & 59 & UPDRS III & $>20 \%$ & Only one & $>3$ months & $\begin{array}{l}\text { APO } \\
\text { Chronic LD }\end{array}$ & $\begin{array}{l}2 \text { or } 3 / 4 \text { or } 5 \\
<800\end{array}$ \\
\hline Schwartz ${ }^{12}$ & 1993 & 83 & UPDRS III & $>20 \%$ & Only one & $>4$ months & $\begin{array}{l}\text { APO } \\
\text { Chronic LD }\end{array}$ & $\begin{array}{l}2,3,5 \\
<1000\end{array}$ \\
\hline $\mathrm{D}^{\prime} \operatorname{Costa}^{9}$ & 1995 & 22 & $\begin{array}{l}\text { Tapping } \\
3 \mathrm{~m} \text { walk }\end{array}$ & $\begin{array}{l}>20 \% \\
>20 \%\end{array}$ & One of two & 1 month & $\begin{array}{l}\text { Acute LD } \\
\text { Chronic LD }\end{array}$ & $\begin{array}{l}125 \\
375\end{array}$ \\
\hline
\end{tabular}

$\mathrm{APO}=$ Apomorphine; $\mathrm{LD}=$ levodopa. 


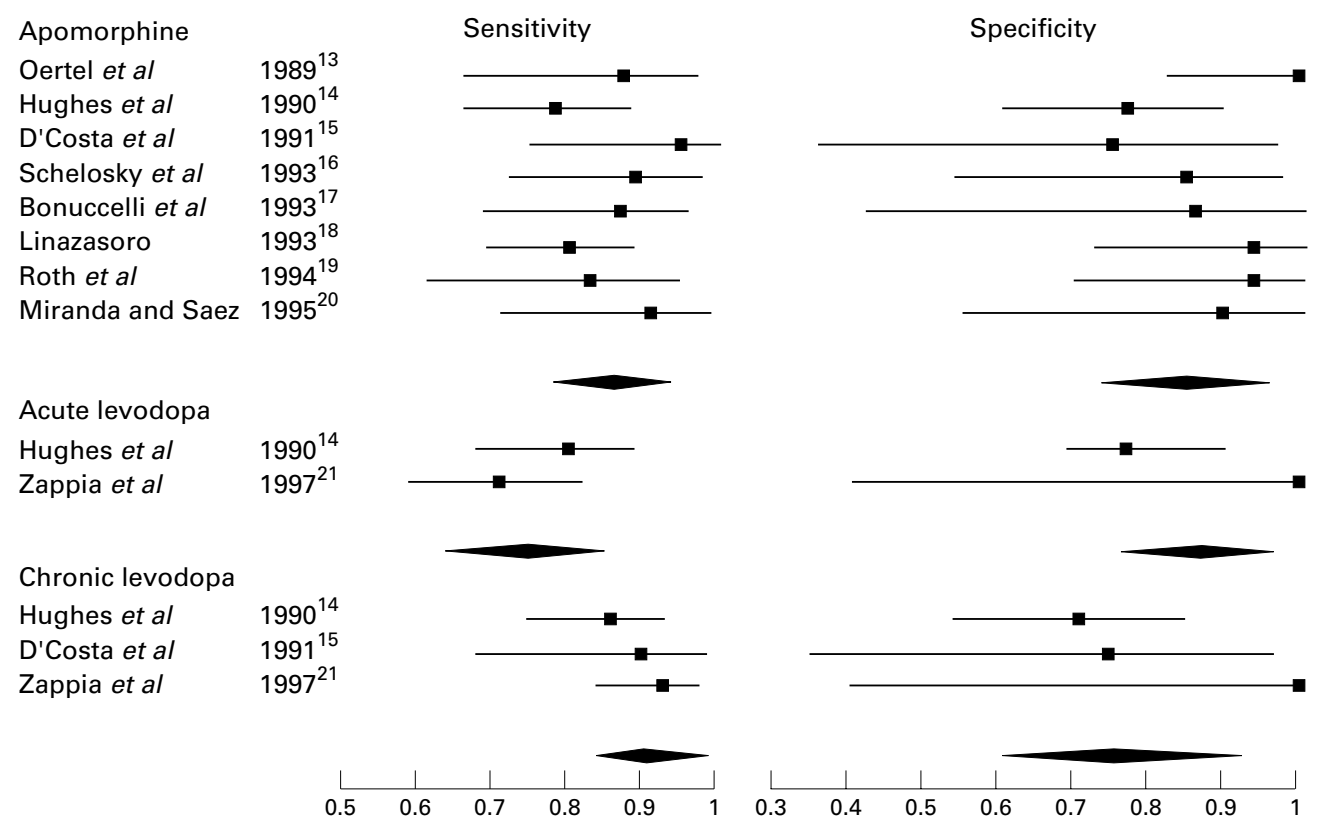

Figure 1 Meta-analysis of sensitivity and specificity of apomorphine, acute levodopa, and chronic levodopa challenge tests in patients with an established clinical diagnosis of idiopathic Parkinson's disease or other condition.

the surprising agreement in the results, explored further below, argues that the measures used were comparable in practice.

Similar heterogeneity was seen in the methodology of the challenge studies in newly diagnosed patients (table 2).

Using meta-analysis weighted for the number of patients in each study (fig 1), the sensitivity for the diagnosis of idiopathic Parkinson's disease with apomorphine challenge was 0.86 (95\% CI 0.78-0.94) compared with 0.75 (95\% CI $0.64-0.85)$ for acute levodopa challenge and 0.91 (95\% CI $0.85-$

Apomorphine

$\begin{array}{ll}\text { Hughes et al } & 1990^{14} \\ \text { Gasser et al } & 1992^{11} \\ \text { Schwartz et al } & 1993^{12}\end{array}$

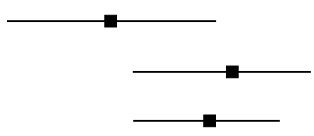

Acute levodopa

$\begin{array}{ll}\text { Hughes et al } & 1990^{14} \\ \text { D'Costa et al } & 1991^{15}\end{array}$

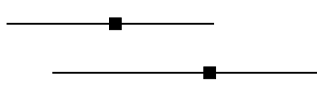

Chronic levodopa

$\begin{array}{ll}\text { Hughes et al } & 1990^{14} \\ \text { Gasser et al } & 1992^{11} \\ \text { Schwartz et al } & 1993^{12} \\ \text { D'Costa et al } & 1991^{15}\end{array}$
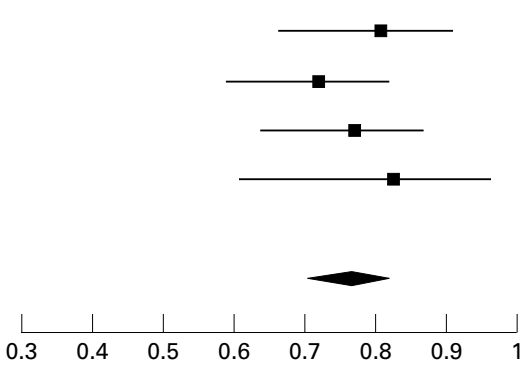

Figure 2 Meta-analysis of apomorphine, acute levodopa, and chronic levodopa challenge tests in patients with newly diagnosed idiopathic Parkinson's disease.
0.99) for chronic levodopa therapy (fig 1). The specificity for the diagnosis of idiopathic Parkinson's disease with apomorphine challenge was 0.85 (95\% CI 0.74-0.96) compared with 0.87 (95\% CI $0.77-0.97)$ for acute levodopa challenge and 0.77 (95\% CI $0.61-$ 0.93 ) for chronic levodopa therapy (fig 1 ). Neither heterogeneity tests in the meta-analysis nor logistic regression analysis comparing the odds ratios of different studies showed any signs of statistically significant variation between studies in sensitivities or specificities.

In only three study reports was it possible to cross correlate the responses of individual patients to apomorphine or levodopa with chronic levodopa therapy. As such studies are the only satisfactory way of comparing challenge tests because of possible population differences from study to study, this would in principle suggest the need for more studies of this type. With the studies of Hughes et $a l^{14}$ and pare apomorphine and chronic levodopa therapy outcomes, a total of 68 patients with idiopathic Parkinson's disease received a correct positive outcome by both tests, nine patients a negative outcome by both tests, six were positive by chronic levodopa but negative by apomorphine, and two were negative by chronic levodopa but not apomorphine. However, conditional logistic regression analysis showed that the odds ratio for misclassification rate between the two tests of 3.0 (95\% CI 0.60-14.9) was not statistically significant.

With the studies of Hughes et $a l^{14}$ and Zappia et $a l,{ }^{21}$ for which it was possible to compare acute levodopa and chronic levodopa outcomes, a total of 100 patients with idiopathic Parkinson's disease received a correct positive outcome by both tests and 12 patients a negative outcome by both tests. However, 21 chronic levodopa positive patients were negative by acute levodopa and two patients were negative by chronic d'Costa et $a l^{15}$ for which it was possible to com- 
levodopa but not acute levodopa. The odds ratio for misclassification rates of 10.5 (95\% CI 2.544.8) was statistically significant in favour of chronic levodopa therapy $(\mathrm{p}<0.001)$.

In de novo patients thought clinically to have idiopathic Parkinson's disease considerable diagnostic uncertainty remains as they have not been followed up clinically for as long as those examined above. As a result, the true sensitivity of the tests cannot be computed, so the number of positives/all patients thought to have idiopathic Parkinson's disease ("fraction positive") has been used as a surrogate for sensitivity. Using a weighted meta-analysis (fig 2), the "fraction positive" for the apomorphine test was $0.69(95 \%$ CI $0.59-0.80)$, for the acute levodopa test it was 0.63 (95\% CI $0.56-0.70)$, and for chronic levodopa therapy 0.76 (95\% CI $0.70-0.82$ ). There was no statistically significant variation within studies for any of these tests.

\section{Discussion}

This systematic review has documented methodological issues for these acute challenge tests (tables 1 and 2). The number of patients evaluated in each study was small, the largest being a mixture of 100 patients with presumed idiopathic Parkinson's disease and nonparkinsonian disease. Considerable variation occurred in the methodology used in these studies, particularly in the thresholds used to define a positive response and the number of abnormal tests required to define an abnormal response. There was also variation in the apomorphine administration regime for dose and interval between doses. Despite this heterogeneity in design, meta-analysis and logistic regression failed to show any heterogeneity between studies (fig 1). Certainly, if these tests were to be adopted on a wider scale then further work would be required to define which assessments to use, what thresholds to take, and what dose of apomorphine to use. The final regime would then need to be tested prospectively in many patients before it could be universally accepted.

The "simplicity" of these tests is often hailed as a valuable feature. However, they have significant drawbacks. Despite the use of domperidone pretreatment for 1 or 2 days, itself a complicating factor adding expense to the tests, many patients have adverse events after apomorphine. Day case admission or at least prolonged observation in a clinic by an experienced member of staff is required as a result. This leads to a not insignificant burden to the patient in adverse events and the healthcare system in cost with little to show in terms of concrete results.

Meta-analysis of those studies examining the tests in established idiopathic Parkinson's disease and non-parkinsonian disease (fig 1) showed that the sensitivity and specificity for both the acute apomorphine and acute levodopa challenges did not differ much from the response to chronic levodopa therapy. This was corroborated by analysis of cross correlation in the paired responses of patients to each test available for a few of the studies. Because standard practice for many years has been to treat patients with long term levodopa after a diagnosis of idiopathic Parkinson's disease has been made, the acute challenge tests are redundant, not adding any value to the response to chronic levodopa. In recent years, the desire to avoid levodopa therapy in younger patients to delay the onset of motor complications has led to the use of dopamine agonist monotherapy. ${ }^{22}$ It could be argued that the results of an apomorphine challenge test in such patients may be of value. However, the response to a sufficient dose of an agonist after several months is likely to be similar to that to chronic levodopa judging from recent studies. ${ }^{22}$ Although objective confirmation is required, it is likely that an acute apomorphine challenge would offer little additional diagnostic certainty to chronic agonist monotherapy.

It is early in the course of an akinetic-rigid syndrome that these tests are required to differentiate idiopathic Parkinson's disease from other conditions. Such tests are of less value later in the disease when other clinical features have given rise to the strong suspicion of another condition (for example, disproportionate imbalance and falls in progressive supranuclear palsy, autonomic dysfunction in multiple system atrophy). At this earlier stage, acute apomorphine and levodopa challenges seem even less impressive in comparison to chronic levodopa therapy (fig 2).

The reasons for the low sensitivity and specificity of these tests is likely to be twofold. The United Kingdom Parkinson's Disease Society Brain Bank study ${ }^{1}$ showed that some patients with pathologically confirmed Lewy body disease failed to respond to chronic levodopa therapy in life and would presumably have failed to respond to acute challenge tests. Conversely, patients with multiple system atrophy can paradoxically respond to levodopa therapy, at least in the early stages of the disease. Thus, acute challenge tests with apomorphine and levodopa are more a marker of the response to dopaminergic medication than an indication of the underlying pathological process. The corollary of this is that acute challenges may still be of value in patients with established idiopathic Parkinson's disease when there is doubt about their response during prolonged off periods.

In conclusion, this systematic review has shown that the diagnostic accuracy of the acute levodopa and apomorphine challenge tests is comparable with that of chronic levodopa therapy in the differentiation of idiopathic Parkinson's disease from its mimics. However, they add no additional diagnostic information, especially in early disease. As long term levodopa therapy, or dopamine agonist monotherapy, will be required in all patients anyway, it is suggested that these acute tests do not add any value to the diagnostic ability of chronic dopamimetic therapy. These tests also suffer from a significant incidence of adverse events, the need for domperidone pretreatment, a lack of agreement on what assessment methods to use, disagreement on threshold responses, the need for day case admission, and significant cost. It is suggested that the diagnosis of 
idiopathic Parkinson's disease continues to rest on clinical features, the response to chronic dopamimetic therapy, and long term clinical follow up.

1 Hughes AJ, Daniel SE, Kilford L, et al. Accuracy of clinical diagnosis of idiopathic Parkinson's disease: a clinicopathological study of 100 cases. F Neurol Neurosurg Psychiatry 1992;55:181-4

2 Eardley I, Quinn NP, Fowler CJ, et al. The value of urethral sphincter electromyography in the differential diagnosis of parkinsonism. Br f Urol 1989;64:360-2.

3 Kimber JR, Watson L, Mathias CJ. Distinction of idiopathic Parkinson's disease from multiple-system atrophy by stimulation of growth-hormone release with clonidine. Lancet 1997;349:1877-81.

4 Clarke CE, Ray PS, Speller JM. Failure of the clonidine growth hormone stimulation test to differentiate multiple system atrophy from advanced idiopathic Parkinson's disease. Lancet 1999;353:1329-30.

5 Tranchant C, Guiraud-Chaumeil C, Warter JM. Stimulation of growth hormone release with clonidine is not a good tion of growth hormone release with clonidine is not a good test to distinguish Parkinson's disease from
atrophy. Mov Disord 1998;13(suppl 2):197.

6 Brooks DJ. PET and SPECT studies in Parkinson's disease. In: Quinn NP, ed. Parkinsonism. London: Bailliere Tindall; In: Quinn NP,

7 Schulz JB, Skalej M, Wedekind D, et al. Magnetic resonance imaging-based volumetry differentiates idiopathic Parkinson's disease from multiple system atrophy and progressive supranuclear palsy. Ann Neurol 1999;45:65-74.

8 Fleiss JL. Statistical methods for rates and proportions. Chichester: John Wiley, 1973

9 D Costa DF, Sheehan LJ, Phillips PA, et al. The levodopa test in Parkinson's disease. Age Ageing 1995;24:210-2.

10 Hughes AJ, Lees AJ, Stern GM. Challenge tests to predict the dopaminergic response in untreated Parkinson's disease. Neurology 1991;41:1723-5.
11 Gasser T, Schwarz J, Arnold G, et al. Apomorphine test for dopaminergic responsiveness in patients with previously untreated Parkinson's disease. Arch Neurol 1992;49:11314.

12 Schwarz J, Tatsch K, Arnold G, et al. ${ }^{123}$ I-iodobenzamideSPECT in 83 patients with de novo parkinsonism. Neurology 1993;43(suppl 6):S17-20.

13 Oertel WH, Gasser T, Ippisch R, et al. Apomorphine test for dopaminergic responsiveness. Lancet 1989;335:1262-3.

14 Hughes AJ, Lees AJ, Stern GM. Apomorphine test to predict dopaminergic responsiveness in parkinsonian syndromes. Lancet 1990;336:32-4.

15 D Costa DF, Abbott RJ, Pye IF, et al. The apomorphine test in parkinsonian syndromes. F Neurol Neurosurg Psychiatry 1991;54:870-2.

16 Schelosky L, Hierholzer J, Wissel J, et al. Correlation of clinical response in apomorphine test with D2-receptor status as demonstrated by ${ }^{123} \mathrm{I}$ IBZM-SPECT. Mov Disord 1993;8:453-8.

17 Bonuccelli U, Piccini P, Del Dotto P, et al. Apomorphine test for dopaminergic responsiveness: a dose assessment study. Mov Disord 1993;8:158-64.

18 Linazasoro G. The apomorphine test in Parkinson's disease: diagnostic value. Neurologia 1993;8:288-90.

19 Roth J, Ruzicka E, Mecir P. The apomorphine test in the differential diagnosis of Parkinsonism. Initial experience. Cas Lek Cesk 1994;133:665-7.

20 Miranda M, Saez D. Apomorphine test: evaluation of dopaminergic response in patients with Parkinson disease. Rev Med Chil 1995;123:326-9.

21 Zappia M, Montesanti R, Colao $\mathrm{R}$, et al. Short-term levodopa test assessed by movement time accurately predicts dopaminergic responsiveness in Parkinson's disease. Mov Disord 1997;12:103-6.

22 Rascol O, Brooks D, Korczyn A, et al. A five year study of the incidence of dyskinesia in patients with early Parkinson's desease who were treated with ropinirole or levodopa. N Engl f Med 2000;342:1484-91. 